\title{
Quantitative and Comparative Analysis of Urinary Steroid Levels upon Treatment of an Anti-Diabetic Drug, CKD-501 using Gas Chromatography-Mass Spectrometry
}

\author{
Krishna Chaitanya Sadanala,2, Byung Hwa Jung,2, In Jin Jang ${ }^{3}$ and Bong Chul Chung ${ }^{1,2 \uparrow}$ \\ ${ }^{1}$ Integrated Omics Center, Korea Institute of Science and Technology, Seoul 136-791, Republic of Korea \\ ${ }^{2}$ University of Science and Technology, (305-333) 113 Gwahangno, Yuseong-gu, Daejeon, Korea \\ ${ }^{3}$ Department of Pharmacology, Clinical Pharmacology \& Clinical Trials Center, \\ Seoul National University College of Medicine \& Hospital, Seoul, Republic of Korea \\ (Received January 26, $2011 \cdot$ Revised February 16, $2011 \cdot$ Accepted February 17, 2011)
}

\begin{abstract}
Urinary steroid levels were investigated in the treatment of CKD-501, a new anti-diabetic drug candidate. CKD-501 was administered orally at the dosage of $1,2,4 \mathrm{mg} /$ day for 7 days to normal men $(\mathrm{n}=18)$. Urine was collected before, during and after stopping the drug administration and the urinary level of androgen, estrogen, progestin and corticoids were quantified using GC-MS (gas chromatography-mass spectrometry). Only urinary corticosteroid and an androgen, DHEA levels among all the analyzed steroids, have been found to increase progressively, reaching significant levels on the last day of drug treatment and later declined after the drug treatment is withdrawn. Therefore, it was thought that an increase in the urinary corticoid and DHEA levels could be a characteristic of CKD-501, since it prominently acts on the glucose sensitivity and suppresses the triglyceride levels. In conclusion, it was found that CKD-501, an anti-diabetic drug candidate, affects the glucocorticoid and DHEA levels and it plays a crucial role in glucose homeostasis.
\end{abstract}

Key words - CKD-501, Diabetes, Steroids, GC-MS, PPAR (Peroxisome proliferator-activated receptor)

Type-2 diabetes evolves from a state of insulin resistance with hyperinsulinemia necessary to maintain glucose tolerance. Type-2 diabetes is manifested when insulin secretion fails to meet the demands, with consequent hyperglycemia and eventual pancreatic $\beta$-cell failure (Tomilson et al., 2008). Recent findings on the progression of type-2 diabetes mellitus indicate that the insulin resistance in peripheral tissues induces compensatory hyperinsulinemia, followed by $\beta$-islet cell failure, initially leading to prandial pain and subsequently to obvious fasting hyperglycemia (Harris et al., 1998; Jay et al., 2007). Peroxisome proliferator-activated receptors (PPARs), which are largely expressed in adipose tissue in comparison to the skeletal muscle and liver tissue, are ligand-inducible transcription factors that belong to the nuclear hormone receptor superfamily (Hevener et al., 2007; Norgren et al., 2004). Thiazolidinediones (TZDs)-based PPAR activators, such as CKD501, rosiglitazone, and pioglitazone, are believed to intensify the action of insulin, thus promoting the utilization of glucose in peripheral tissues, and as a result, are therapeutically useful in the management of type-2 diabetes (Ferre et al., 2004; Orasanu et al., 2008). In the human ACTH-responsive NCI h295 adrenocortical cancer cell line, TZDs decrease prolif-

\footnotetext{
Corresponding Author:

Tel : +82-2-958-5062, E-mail : bcc0319@kist.re.kr

DOI : 10.4333/KPS.2011.41.1.037
}

eration and viability but increase ACTH receptor (MC2R) expression, cortisol secretion, and apoptosis (Betz et al., 2005).

CKD-501 is a new anti-diabetic drug candidate. Its key ingredient is lobeglitazone sulfate, and its mechanism is PPAR gamma agonist. The structure of CKD-501 is given in Figure 1. CKD-501 might improve the hyperglycemia by increasing GLUT-5 (Glucose Transporter 5) translocation, leading to the stimulation of glucose transport, and the elevation of intracellular calcium level might play an important role in this stimulation. CKD-501, glytazone family insulin sensitizor, enhances insulin sensitivity, glucose homeostasis, and it shows fewer side effects (hypoglycemia, shock etc) when compared with that of other anti-diabetic drugs. Furthermore, it also has potent triglyceride lowering activity and significantly improves the half-life when compared to rosiglitazone.

It has been reported that the steroid levels increase in the treatment of anti-diabetic drugs. Steroids are involved in the glucose and lipid metabolism and they are also a part of metabolites of lipids. Excess intake of glucose and fat plays a crucial role in the genesis of diabetes; inversely their level and related steroid level could be changed in the biological fluids after anti-diabetic drug treatment. Besides their well-known effects on insulin sensitivity and energy metabolism, TZDs have also been reported to modulate steroid production in gonad tissues. For example, TZDs stimulate progesterone secretion in MA-10 Leydig tumor cells (Freeman et al., 2003; Kempna et al., 2007) 


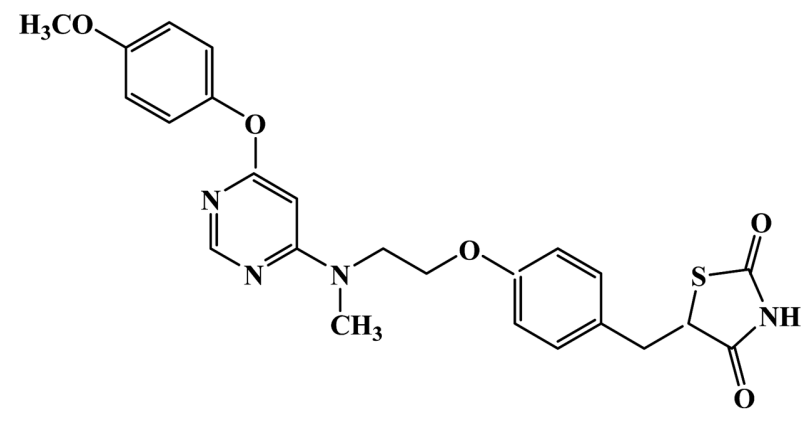

Figure 1. Structure of CKD-501.

and ovarian cells (Froment et al., 2003). In this study, the urinary steroid levels were monitored to check the effect of CKD501 using gas chromatography-mass spectrometry. CKD-501 is a new drug candidate in the category of anti-diabetic drugs. Hence, this monitoring process can provide useful information regarding the suitability of drug action.

\section{Materials and Methods}

\section{Subjects}

Male subjects $(n=18)$, were recruited for this study. CKD501 was orally administered at the dosage of 1,2 and $4 \mathrm{mg} /$ day for 7 days. The urine was collected before and at the end of drug treatment, $6 \mathrm{hr}$ on 7 th day. The urine was collected again after stopping the drug administration ( 8 day, $0 \mathrm{hr}$ ). The collected urine was stored at $-20^{\circ} \mathrm{C}$ till the time of analysis.

\section{Reagents}

Steroids were purchased from Steraloids Inc. (Newport, R.I., USA). $\beta$-glucuronidase ( $\beta$-glucuronidase activity: $400-600 \mathrm{U} /$ $\mathrm{mL}$ ) was purchased from Roche Diagnostics $\mathrm{GmbH}$ (Penzberg, Germany). N-methyl-N-(trimethylsilyl) trifluoroacetamide (MSTFA), ammonium iodide $\left(\mathrm{NH}_{4} \mathrm{I}\right)$ and dithioerythreitol (DTE) were also supplied by Sigma-Aldrich Chemicals Co. (St. Louis, MO, USA). Methanol, ethyl acetate and n-hexane were bought from SK Chemicals (Ulsan, Republic of Korea, HPLC grade). Ultrapure water (18.2 M $\Omega$ ) was obtained using MilliQ apparatus from Millipore (Milford, USA).

\section{Quantitative analysis of urinary steroids}

Androgen, estrogen, progestins and corticosteroids were quantified in urine by following the method reported (Moon et al., 2009). Prior to sample preparation, $20 \mu \mathrm{L}$ of seven internal standard mixtures $\left(\mathrm{d}_{3}\right.$-testosterone and $\mathrm{d}_{4}$-estradiol $1 \mu \mathrm{g} / \mathrm{mL}$, methyltestosterone, $d_{6}$-cholesterol and $d_{9}$-progesterone $10 \mu \mathrm{g} /$ $\mathrm{mL}, \mathrm{d}_{4}$-cortisol and $\mathrm{d}_{8}-17 \alpha-\mathrm{OH}$-progesterone $5 \mu \mathrm{g} / \mathrm{mL}$ ) was added to $0.5 \mathrm{~mL}$ of urine. Solid phase extraction (SPE) was carried out using an Oasis HLB cartridge (Waters, Milford, USA). The cartridge was preconditioned with $2 \mathrm{~mL}$ of methanol (HPLC grade) and $2 \mathrm{~mL}$ of deionized water. After preconditioning, the sample was loaded in to the cartridge, and the solutes were eluted twice with $2 \mathrm{~mL}$ of methanol. This was followed by evaporation under a gentle stream of nitrogen gas. After adding $1 \mathrm{~mL}$ of Phosphate buffer (0.2 M, pH 7.2) and $50 \mu \mathrm{L}$ of $\beta$-glucuronidase to the residue, enzyme hydrolysis was carried out at $55^{\circ} \mathrm{C}$ for $1 \mathrm{~h}$. Liquid-liquid extraction, using $2.5 \mathrm{~mL}$ of ethylacetate:n-hexane $(2: 3)$, was then performed twice. The organic phase was separated by centrifuging for $5 \mathrm{~min}$ at $2500 \mathrm{rpm}$; and after freezing $\left(-25^{\circ} \mathrm{C}\right)$ for $5 \mathrm{~min}$, the supernatant was transferred. The supernatant was dried using a gentle stream of nitrogen gas at $37^{\circ} \mathrm{C}$, before being maintained in a vacuum dessicator over $\mathrm{P}_{2} \mathrm{O}_{5} / \mathrm{KOH}$ for at least $30 \mathrm{~min}$. For derivatization, a $40 \mu \mathrm{L}$ mixture of MSTFA, $\mathrm{NH}_{4} \mathrm{I}$ and DTE (500:4:2, v/w/w) was added to the dried residue and reacted at $60^{\circ} \mathrm{C}$ for $20 \mathrm{~min}$. Next, a $2 \mu \mathrm{L}$ of aliquot was used for the gas chromatography-mass spectrometry (GC-MS). The urinary steroids were analyzed by GC-MS using an Agilent 6890 series gas chromatograph and an Agilent 5975 series mass selective detector. The samples were injected into a fused-silica capillary column that was coated with cross linked methyl silicone (Ultra- $1,25 \mathrm{~m}$ length $\times 0.2 \mathrm{~mm}$ i.d., $0.33 \mu \mathrm{m}$ film thickness) by an Agilent 7683 B series auto-sampler. The carrier gas was helium and a constant flow rate of $1 \mathrm{~mL} / \mathrm{min}$ was applied. The inlet temperature was $280^{\circ} \mathrm{C}$ and the split ratio was $10: 1$. The oven temperatures were as follows: the initial temperature was $215^{\circ} \mathrm{C}$; this was raised to $260^{\circ} \mathrm{C}$ at a rate of $1^{\circ} \mathrm{C} / \mathrm{min}$; and finally, it was increased to $320^{\circ} \mathrm{C}$ at a rate $15^{\circ} \mathrm{C} / \mathrm{min}$ for a period of $1 \mathrm{~min}$. The ion source and detector temperatures were $150^{\circ} \mathrm{C}$ and $230^{\circ} \mathrm{C}$, respectively. The auxiliary temperature was $300^{\circ} \mathrm{C}$. The ionization mode was the electron impact (EI) ionization mode. All the ions were monitored in the selected ion monitoring (SIM) mode.

\section{Urinary creatinine value}

All the concentrations calculated from the calibration curves were revised according to the respective urinary creatinine values. The urinary creatinine value of each sample was measured by Jaffe method (Kassirer et al., 1971).

\section{Results}

The urinary steroids have shown an increase in their levels upon drug administration, and have shown a decline after stopping the drug administration. The total ion chromatogram obtained was shown in Figure 2. Among the four major groups 
of steroids analyzed, a prominent change was observed in the urinary corticoids concentration profile. A significant increase in urinary corticoid levels was found in all the three dosage groups on the last day of drug administration in comparison to their levels before drug administration and immediately after drug withdrawal. The significant pattern of changes in corticoid levels in low dosage group ( $1 \mathrm{mg} /$ day) were detailed in Figure 3 . In the medium dosage group ( $2 \mathrm{mg} /$ day), similar pat-

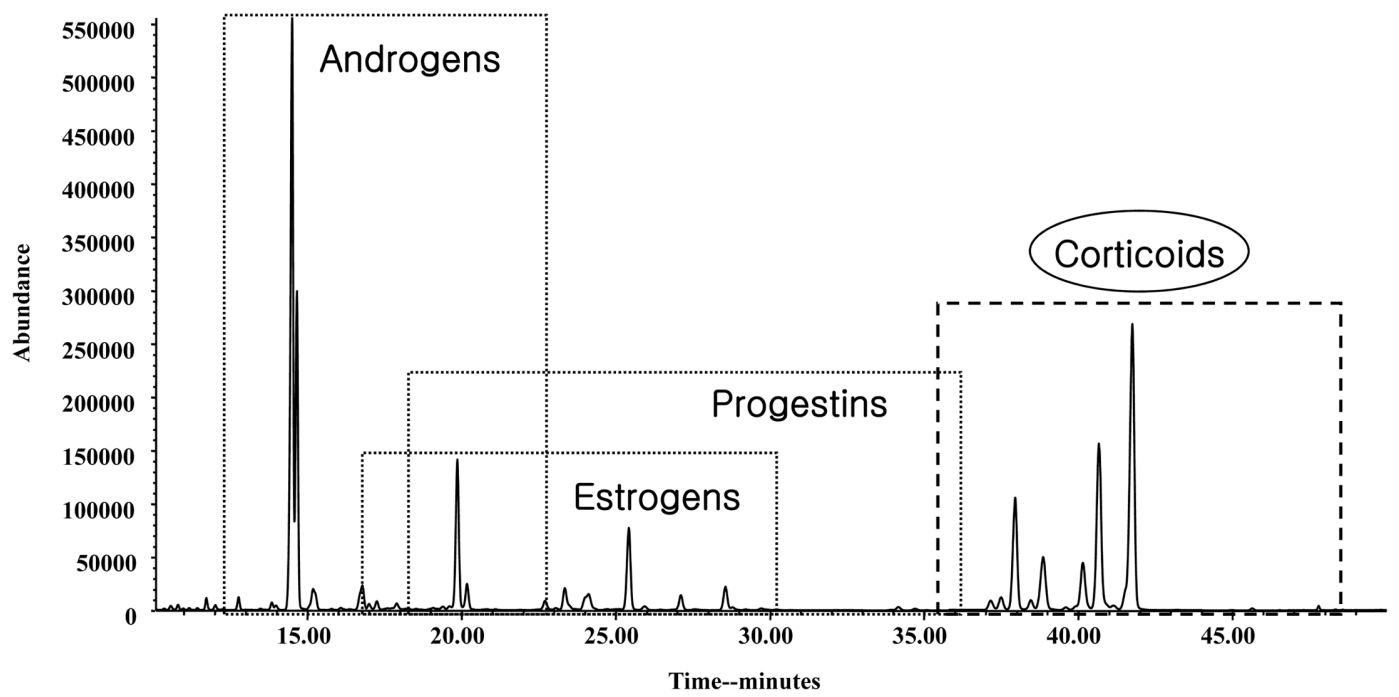

Figure 2. A representative total ion chromatogram of steroids detected by GC-MS in 7th day 6th hour urine of the drug treated subjects.
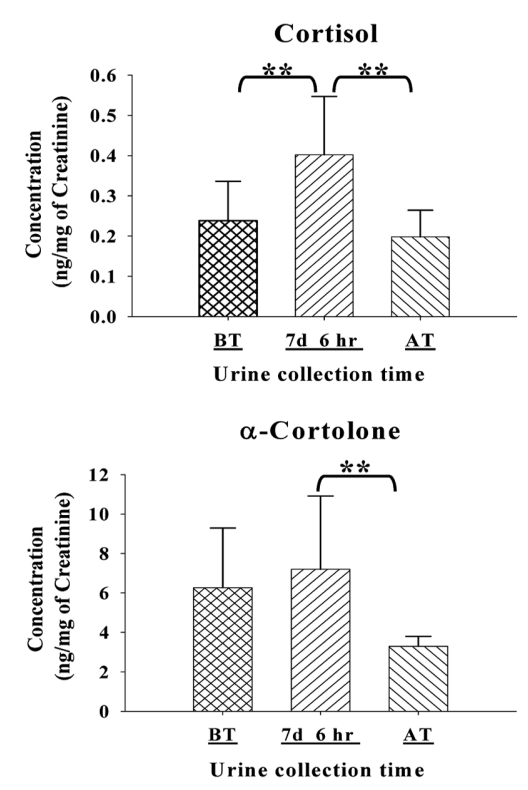

$\alpha$-Cortol

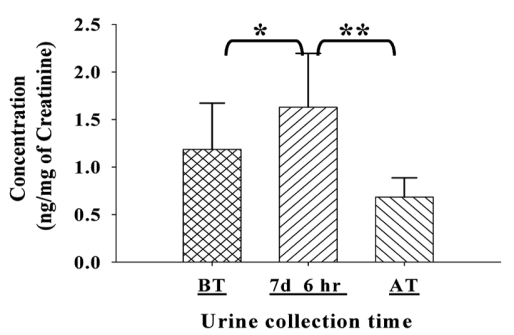

Tetrahydrocortisone

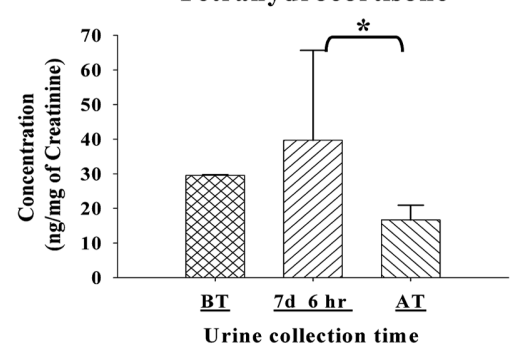

$\beta$-Cortolone

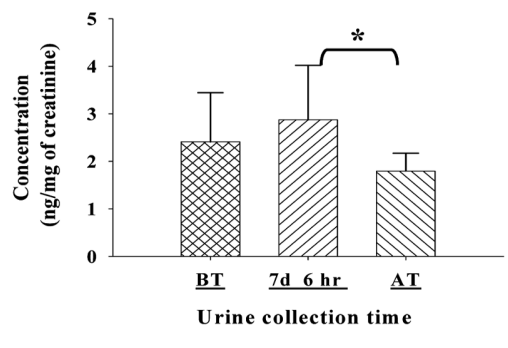

$\beta$-Cortol

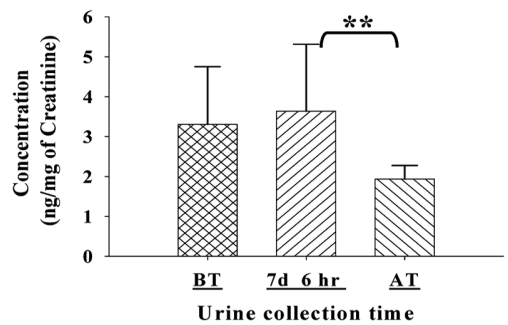

Tetrahydrocortisol

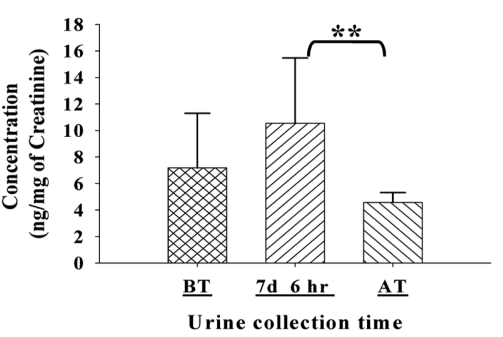

20- $\alpha$-Dihydrocortisone

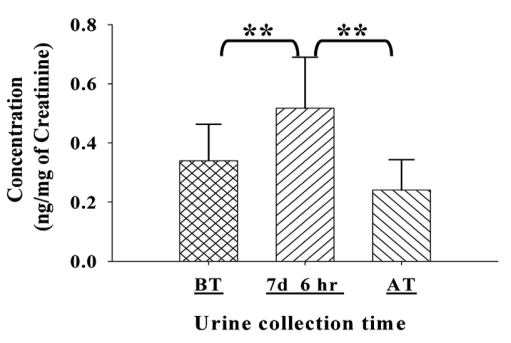

20- $\alpha$-Dihydrocortisol

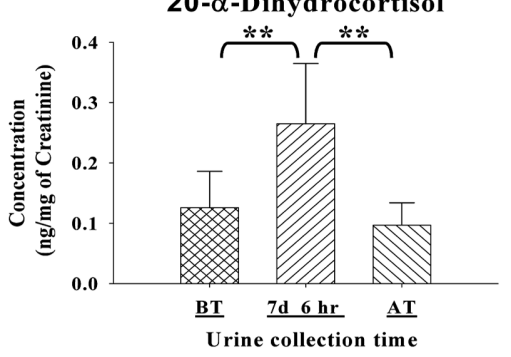

Figure 3. Glucocorticoid metabolites detected in the urine of CKD-501 treated subjects $-1 \mathrm{mg} /$ day dosage group. [BT: before drug treatment, AT: after drug treatment, $7 \mathrm{~d} 6 \mathrm{hr}$ : last day of drug treatment; $\left.{ }^{*} \mathrm{P} \leq 0.05, * * \mathrm{P} \leq 0.01, * * * \mathrm{P} \leq 0.001\right]$ 

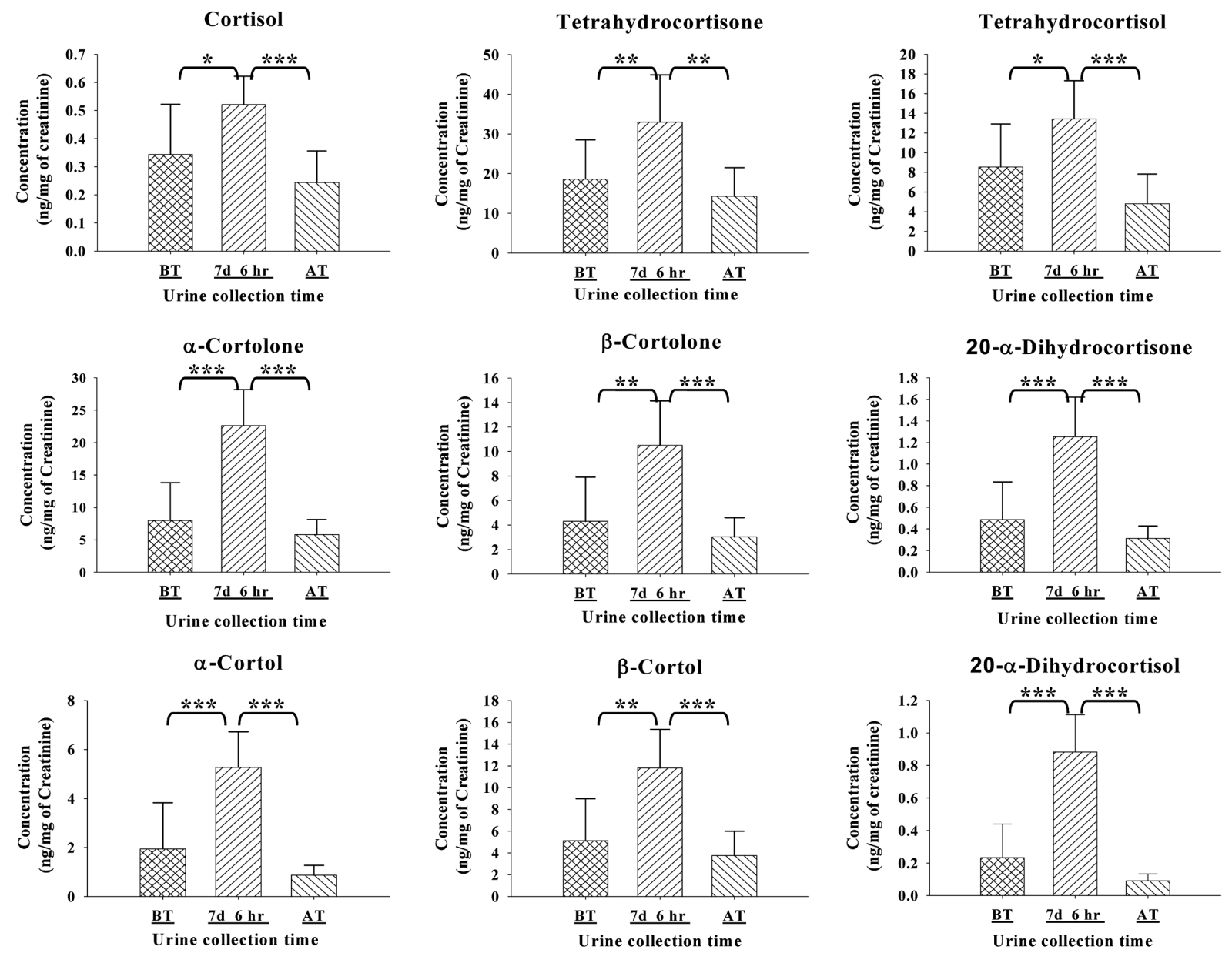

Figure 4. Glucocorticoid metabolites detected in the urine of CKD-501 treated subjects $-2 \mathrm{mg} /$ day dosage group. [BT: before drug treatment, AT: after drug treatment, 7d 6hr: last day of drug treatment; $* \mathrm{P} \leq 0.05, * * \mathrm{P} \leq 0.01, * * * \mathrm{P} \leq 0.001$ ]

tern of changes in corticosteroid levels with more significance was observed (Fig. 4). The high dosage group (4 mg/day) also has shown the similar pattern as compared to results obtained in other two dosage groups (Fig. 5). Among the other groups of steroids besides corticosteroids, an androgen, dehydroepiandrosterone, has shown similar pattern of results as those of corticosteroids in all the three dosage groups (Fig. 6). The representative extracted ion chromatograms of the nine corticoids and an androgen, DHEA were shown in Figure 7.

\section{Method validation}

Calibration curves were generated for all analytes at different concentrations in the range of $0.1 \sim 3000 \mathrm{ng} / \mathrm{mL}$. They were found to be linear (correlation coefficient, $r^{2}>0.989$ ). Most compounds had an LOQ in the $0.05 \sim 2.0 \mathrm{ng} / \mathrm{mL}$ ranges, while those of DHEA, Epi-An, $5 \alpha$-dione, $\alpha \beta \beta$-diol ranged between 5.0 and $50 \mathrm{ng} / \mathrm{mL}$. Assay precisions and accuracies were determined by analyzing three QC samples at different concentrations of the individual steroids $(5,20,100,200,500$, and $2000 \mathrm{ng} / \mathrm{mL}$ ). Intra-day $(n=4)$ precisions (expressed as $\%$ $\mathrm{CV}$ ) ranged from $0.9 \%$ to $11.2 \%$, whereas accuracies (expressed as $\%$ bias) ranged from 95.8 to $119.1 \%$, and inter-day $(n=5)$ precisions $(\% \mathrm{CV})$ and accuracies $(\%$ bias) ranged from $1.6 \%$ to $10.5 \%$ and from $91.6 \%$ to $115.5 \%$, respectively.

\section{Discussion}

CKD-501 (i.e., lobeglitazone), a potent agonist for both PPAR $\alpha / \gamma$, is a new drug that has potential clinical applications in the management of type-2 diabetes (Lee et al., 2009). Peroxisome proliferator-activated receptors ( $\operatorname{PPAR} \alpha, \gamma$, and $\delta$ ) are members of the nuclear receptor family and play a key role in the regulation of adipocyte differentiation, insulin sensitivity, glucose and lipid metabolism, and inflammation (Berthiaume et al., 2007; Blaschke et al., 2006; Desvergne et al., 2004). Some anti-diabetic drugs have shown an increase in the steroid levels in biological fluids (Wang et al., 1997). In the present study, we attempted to study the effects of CKD-501 on steroid 
Cortisol

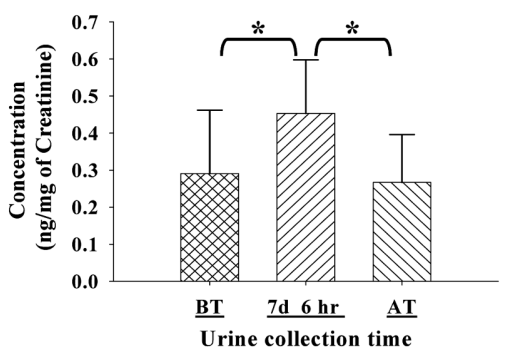

$\alpha$-Cortolone

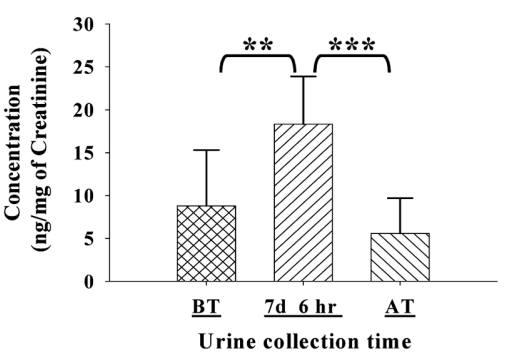

$\alpha$-Cortol

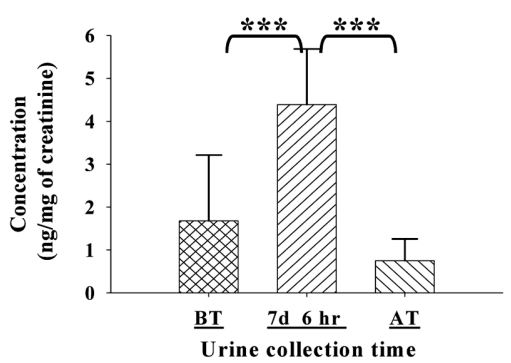

Tetrahydrocortisone

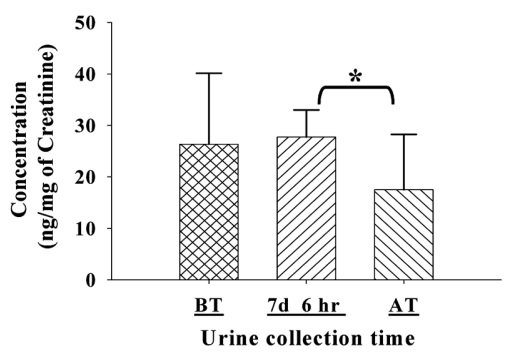

$\beta$-Cortolone
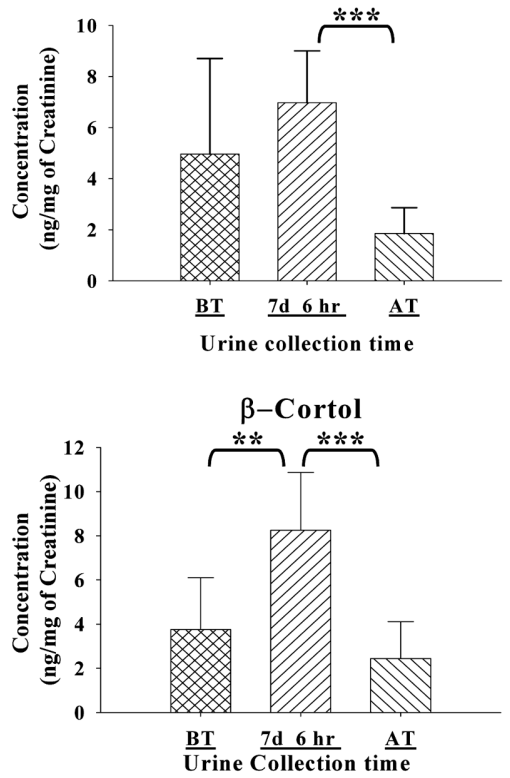

Tetrahydrocortisol

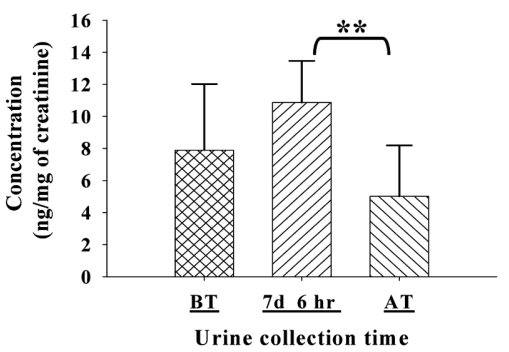

20- $\alpha$-Dihyd rocortisone

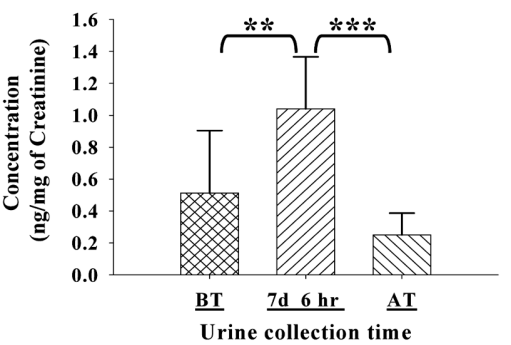

20- $\alpha$ Dihydrocortisol

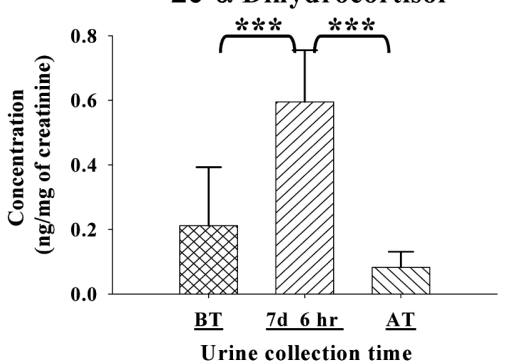

Figure 5. Glucocorticoid metabolites detected in the urine of CKD-501 treated subjects $-4 \mathrm{mg} /$ day dosage group. [BT: before drug treatment, AT: after drug treatment, 7d 6hr: last day of drug treatment; $\left.{ }^{*} \mathrm{P} \leq 0.05,{ }^{*} \mathrm{P} \leq 0.01,{ }^{*} * \mathrm{P} \leq 0.001\right]$

DHEA (1 mg/day)

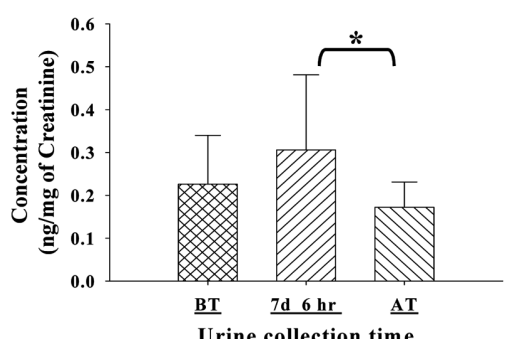

DHEA (2mg/day)

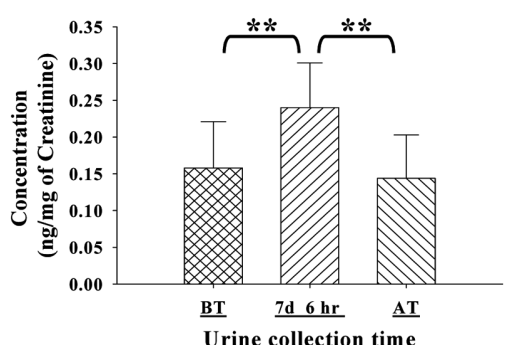

DHEA (4mg/day)

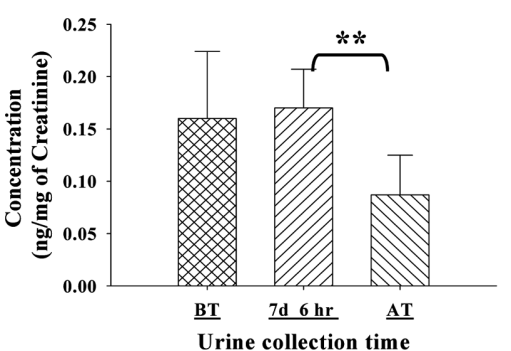

Figure 6. DHEA detected in the urine of CKD-501 treated subjects $-1,2,4 \mathrm{mg} /$ day dosage groups.

[BT: before drug treatment, AT: after drug treatment, 7d 6hr: last day of drug treatment; $* \mathrm{P} \leq 0.05, * * \mathrm{P} \leq 0.01, * * * \mathrm{P} \leq 0.001$ ]

metabolism, analyzing the steroid levels in the human urine samples. According to the results obtained, of all the steroids analyzed, nine glucocorticoids and one androgen levels increased upon the drug treatment than before the drug treatment and decreased after stopping the drug treatment.

Glucocorticoids are steroidal hormones that play an essential role in whole body glucose homeostasis (Baxter et al.; 1979) and are excreted in urine. Therefore, it was thought that the effect of anti-diabetic drug could be evaluated by monitoring the changes in urinary corticosteroid levels. In practice, urinary corticosteroid level was changed by the administration of CKD-501. Similar results on the change of a corticosteroid, corticosterone level in plasma have been reported in the animal studies using lean and fatty zucker rats, in the case of rosigl- 
A: Glucocorticoids
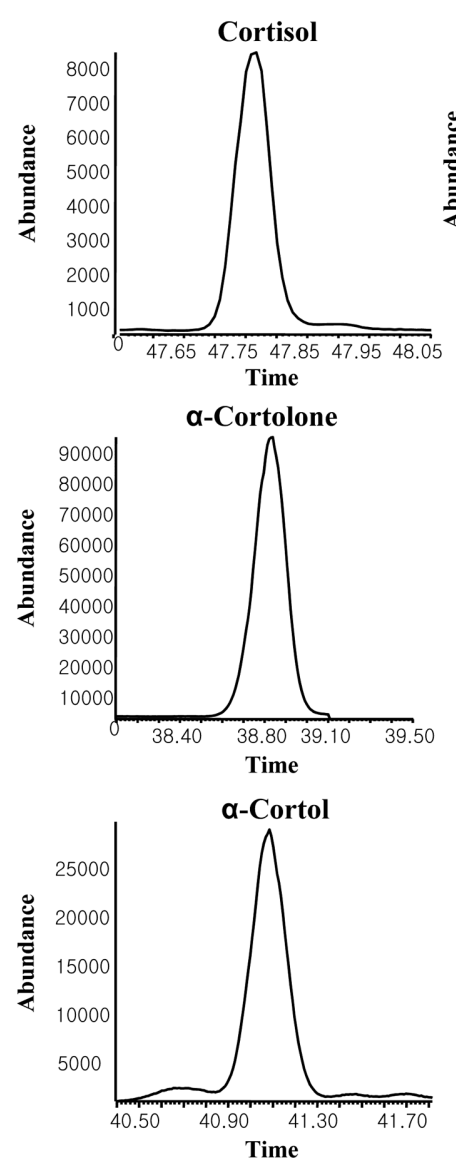
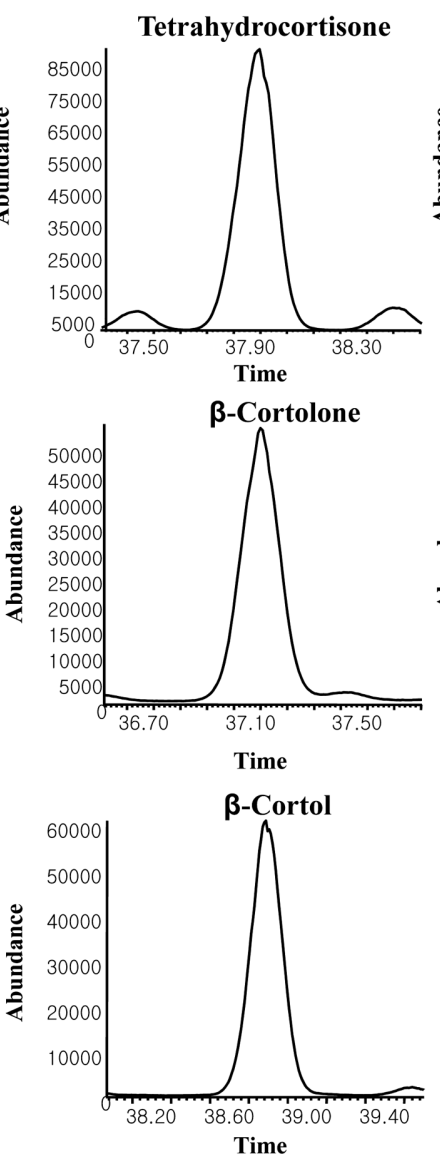

B: Androgen
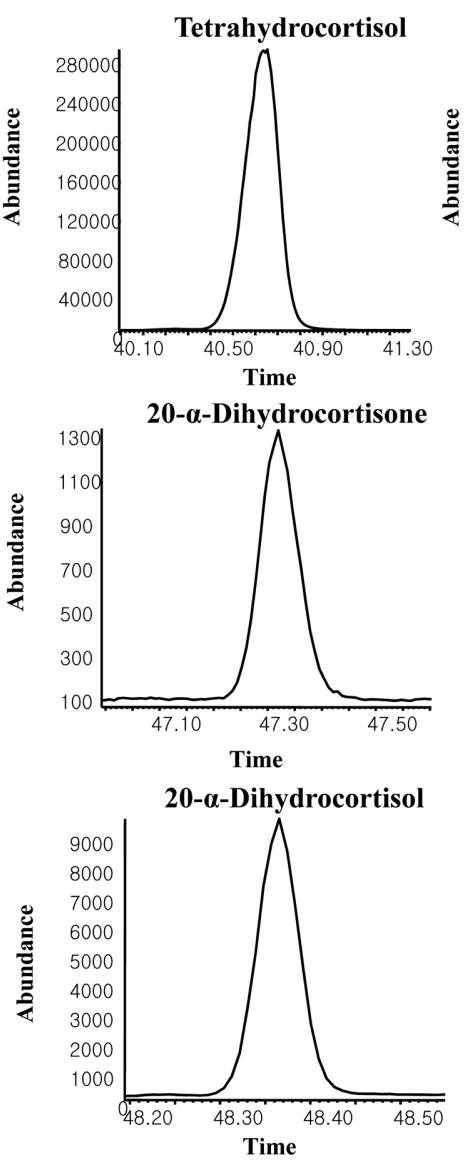

Figure 7. The representative extracted ion chromatograms of the glucocorticoids and an androgen detected by GC-MS in 7 th day 6 th hour urine of the drug treated subjects.

[Glucocorticoids: cortisol, tetrahydrocortisone, tetrahydrocortisol, $\alpha$-cortolone, $\beta$-cortolone, $20-\alpha$-dihydrocortisone, $\alpha$-cortol, $\beta$-cortol, 20 - $\alpha$ dihydrocortisol.; Androgen: dehydroepiandrosterone].

itazone treatment (Wang et al., 1997). In agreement with the published data we attained the results with a broader range of nine corticosteroids in human study. The coticosteroids have shown a significant pattern of increase in their urinary concentration upon administration of a novel anti-diabetic drug, CKD-501 at three dosages in human, thus depicting the effectiveness of the drug upon steroid metabolism.

Another steroid which showed a urinary level change by anti-diabetic drug administration was DHEA (dehydroepiandrosterone), a kind of androgen. DHEA exerts beneficial effects on blood glucose levels and insulin sensitivity in obese rodents and humans, resembling the effects of peroxisome proliferator-activated receptor (PPAR) ligands (Dzhamilja et al., 2006). A growing body of evidence indicates that DHEA plays a significant role in reducing the age-related increase in insulin levels, insulin resistance, and blood glucose; which, in turn, helps to reduce the risks of syndrome $\mathrm{X}$, obesity, cardio vas- cular diseases, and diabetes. The inhibitory effect of DHEA on complex 1 may also partly explain possible anti-diabetic effects of DHEA (Galina et al., 2005). Therefore, it is also possible that the action of anti-diabetic drug could be also checked by the change in urinary DHEA level.

In summary, our results indicate that the levels of corticoids and an androgen, DHEA are increased upon the treatment with CKD-501. Thus, an increase in those steroids, upon CKD-501 treatment, assists in maintaining the glucose balance along with its insulin sensitizer activity and their urinary levels could be used for the monitoring of anti-diabetic drug effects.

\section{Acknowledgements}

This work was supported by a grant from the Ministry of Education, Science and Technology (MEST), and the Korea Institute of Science and Technology. 


\section{References}

Baxter, J.D., Rousseau, G.G., 1979. Glucocorticoid hormone action: an overview. Monogr. Endocrinol. 12, 1-24.

Berthiaume, M., Sell, H., Lalonde, J., Gelinas, Y., Tchernof, A., Richard, D., Deshaies, Y., 2004. Actions of PPAR $\gamma$ agonism on adipose tissue remodeling, insulin sensitivity, and lipemia in absence of glucocorticoids. Am J. Physiol. Regul. Integr. Comp Physiol. 287, R1116-R1123.

Betz, M.J., Shapiro, I., Fassnacht, M., Hahner, S., Reincke, M., Beuschlein, F., 2005. Peroxisome proliferator-activated receptor- $\gamma$ agonists suppress adrenocortical tumor cell proliferation and induce differentiation. J. Clin. Endocrinol. Metab. 90, 3886-3896.

Blaschke, F., Takata, Y., Caglayan, E., Law, R.E., Hsueh, W.A., 2006. Nuclear receptors as potential target for the treatment and prevention of cardiovascular disease. Arterioscler. Thromb. Vasc. Biol. 26, 28-40.

Desvergne, B., Michalik, L., Wahli, W., 2004. Be Fit or Be Sick: Peroxisome proliferator-activated receptors are down the road. Mol. Endocrinol. 18, 1321-1332.

Dzhamilja, S., Nadezhda, P., Enn, S., Alexander, Z., Allen, K., 2006. Dehydroepiandrosterone inhibits complex I of the mitochondrial respiratory chain and is neurotoxic In vitro and In vivo at high concentrations. Toxicological Sciences. 93(2), 348-356.

Ferre, P., 2004. The biology of peroxisome proliferator-activated receptors. Diabetes. 53, S43-S50.

Freeman, D.A., Romero, A., 2003. Effects of troglitazone on intracellular cholesterol distribution and cholesterol-dependent cell functions in MA-10 Leydig tumor cells. Biochem. Pharmacol. 66, 307-313.

Froment, P., Gizard, F., Defever, D., Staels, B., Dupont, J., Monget, P., 2006. PPARs and RXRs in male and female fertility and reproduction. J. Endocrinol. 189, 199-209.

Galina, A., Roberto, A.S.S., Zoltan, B., Radina, M.K., Alex, O., 2005. Dehydroepiandrosterone inhibits the amplification of glucocorticoid action in adipose tissue. Am J. Physiol. Endocrinol. Metab. 288, E957-E964.

Harris, M.I., Flegal, K.M., Cowie, C.C., Eberhardt, M.S., Goldstein, D.E., Little, R.R., Wiedmeyer, H.M., Byrd-Holt, D.D., 1998. Prevalence of diabetes, impaired fasting glucose, and impaired glucose tolerance in U.S. adults. Diabetes Care. 21, 518-524.

Hevener, A.L., Olefsky, J.M., Reichart, D., Nguyen M.T.A., Ban- dyopadyhay, G., Leung, H.Y., Watt, M.J., Benner, C., Febbraio, M.A., Nguyen, A.K., Folian, B., Subramaniam, S., Gonzalez, F.J., Glass, C.K., Ricote, M., 2007. Macrophage PPAR $\gamma$ is required for normal skeletal muscle and hepatic insulin sensitivity and full antidiabetic effects of thiazolidinediones. J. Clin. Invest. 117, 1658-1669.

Jay, M.A., Ren, J., 2007. Peroxisome proliferator-activated receptor (PPAR) in metabolic syndrome and type 2 diabetes mellitus. Curr. Diabetes. 3, 33-39.

Kassirer, J.P., 1971. Clinical evaluation of kidney function - glomerular function. N. Engl. J. Med. 285, 385-389.

Kempná, P., Hofer, G., Mullis, P.E., Flück, C.E., 2007. Pioglitazone inhibits androgen production in NCI-H295R cells by regulating gene expression of CYP17 and HSD3B2. Mol. Pharmacol. 71, 787-798.

Lee, J. H., Woo, T.A., Hwang, I.C., Kim, C. Y., Kim, D. D., Shim, C. K., Chung, S.J., 2009. Quantification of CKD-501, lobeglitazone, in rat plasma using a liquid-chromatography/tandem mass spectrometry method and its applications to pharmacokinetic studies. J. Pharmaceut. Biomed. Anal. 50, 872-877.

Moon, J.Y., Jung, H.J., Moon, M.H., Chung, B.C., Choi, M.H., 2009. Heat-map visualization of gas chromatography-mass spectrometry based quantitative signatures on steroid metabolism. J. Am. Soc. Mass Spectrom. 20, 1626-1637.

Norgren, S., Arner, P., Luthman, H., 1994. Insulin receptor ribonucleic acid levels and alternative splicing in human liver, muscle, and adipose tissue: tissue specificity and relation to insulin action. J. Clin. Endocrinol. Metab. 78, 757-762.

Orasanu, G., Ziouzenkova, O., Devchand, P.R., Nehra, V., Hamdy, O., Horton E.S., Plutzky, J., 2008. The peroxisome proliferator-activated receptor-gamma agonist pioglitazone represses inflammation in a peroxisome proliferator-activated receptoralpha-dependent manner in vitro and in vivo in mice. J. Am. Coll. Cardiol. 52, 869-881.

Tomilson, J.W., Joanne, F., Christopher, G., Hughes, B.A., Susan, V. H., Paul, M. S., 2008. Impaired glucose tolerance and insulin resistance are associated with increased adipose $11 \beta$ hydroxysteroid dehydrogenase type 1 expression and elevated hepatic $5 \alpha$-reductase activity. Diabetes. 57, 2652-2660.

Wang, Q., Dryden, S., Frankish, H. M., Bing, C., Pickavance, L., Hopkins, D., Buckingham, R., Williams, G., 1997. Increased feeding in fatty Zucker rats by the thiazolidinedione BRL 49653 (rosiglitazone) and the possible involvement of leptin and hypothalamic neuropeptide Y. Br. J. Pharmacol. 122, 1405-1410. 